Gentner, D. and Loewenstein, J. (2002). Relational language and

relational thought. Amsel, Eric (Ed); Byrnes, James P. (Ed). Language,

literacy, and cognitive development: The development and consequences

of symbolic communication. pp. 87-120.

\title{
Relational Language and Relational Thought
}

\author{
Dedre Gentner \\ Jeffrey Loewenstein \\ Northwestern University
}

Human cognitive abilities are remarkable. We easily go beyond what is perceptually available to reason about abstract systems. Our cognitive ability to adapt to a vast range of environments, and even to alter our environment to suit our desires, has given our species so great an advantage over other mammals that we are now poised to exterminate most of our former predators, and must use our ingenuity to preserve a few. Indeed, for many theorists, the sophistication of adult human reasoning defies any explanation based on learning.

How do we get so smart? Traditional theories of cognitive development can be grouped into four broad categories. Behaviorist accounts used mechanisms of association and stimulus generalization over perceptual gradients to explain learning, eschewing discussion of mental representations. Current descendants of this view rely on mechanisms such as statistical learning of transitive probabilities. Piagetian constructivism postulated increasingly complex mental representations learned through the child's interactions with the world and cognitive stages characterized by different representational formats and logical operations (Piaget, 1951, 1955). Another constructivist approach is Vygotsky's (1962) theory that abstract cognition develops through the child's interactions with cultural and linguistic systems. The fourth approach, of renewed interest of late, is a nativist approach that postulates that children possess nascent cognitive systems and theories that unfold through interaction with the world. 
The theories of Piaget and Vygotsky offer a rich and appealing view of cognitive development. In particular, Piaget's claim that children can represent and reason over structured knowledge schemas and Vygotsky's claim that language and culture influence cognitive development have remained influential. However, Piagetian stage theory has been challenged by demonstrations of early learning. Further, both theories lack specificity in their accounts of how learning occurs.

The inadequacy of learning mechanisms powerful enough to explain the development of abstract cognition is all the more apparent in light of increasing evidence of the sophistication and generativity of early cognition and language (Mehler \& Dupoux, 1994). The past two decades have seen many striking demonstrations of very early insight into number (Gelman, 1990; Gelman \& Gallistel, 1978), the behavior of objects in space (Baillargeon, 1987, 1991; Spelke, 1988, 1990), and the composition of basic-level categories (Waxman, 1990; Waxman \& Kosowski, 1990). Very young children have been found to categorize (Mandler \& McDonough, 1993) and/or to differentiate between domains based on functional principles (Gelman, 1989; Hirschfeld \& Gelman, 1994; Keil, 1994), and infants were seen to have remarkable early language proficiency (Gleitman \& Wanner, 1982; Pinker, 1994). Children's early achievements vastly outstripped the predictions of the available accounts of learning. The inescapable conclusion, to many theorists, was that much of our knowledge is built in: There must be innate domain-specific principles or skeletal systems that frame our later knowledge.

But perhaps we have dismissed learning too quickly. True, purely behaviorist learning accounts, with minimal representational commitments and mechanisms of simple association and perceptual similarity generalization, cannot account for the acquisition of complex knowledge. And true, Piagetian and Vygotskian approaches have not met our current expectations for theoretical specificity. But we maintain that the richness of constructivist theorizing is compatible with current accounts of learning processes. Our proposal draws on insights from cognitive science models of learning. It is aimed at capturing the development of abstract relational thought-the sine qua non of human cognition.

Relational learning encompasses not only how children acquire abstract relational systems such as mathematics, but also how they learn the theory-like relational information that informs their understanding of ordinary concrete entities. For example, children come to know that both tigers and sharks are carnivores, whereas deer and hippopotamuses are herbivores, that tigers prey on deer, and so on; or, that a taxi is not defined as a yellow car but as a vehicle that can be hired (Keil \& Batterman, 1984). Table 4.1 shows a sample of relational terms, chosen to suggest the range 
TABLE 4.1

A Sampling of Relational Terms

\begin{tabular}{|c|c|c|}
\hline \multicolumn{3}{|c|}{ Spatial Relational Terms } \\
\hline $\begin{array}{l}\text { in } \\
\text { on } \\
\text { under } \\
\text { between } \\
\text { across }\end{array}$ & $\begin{array}{l}\text { bisector } \\
\text { symmetric } \\
\text { monotonic } \\
\text { equilateral } \\
\text { the limit of } \\
y \text { as } x \rightarrow 0\end{array}$ & $\begin{array}{l}\text { approaching } \\
\text { preceding } \\
\text { increasing } \\
\text { passing } \\
\text { half } \\
\text { quarter }\end{array}$ \\
\hline \multicolumn{3}{|c|}{ More Relational Terms } \\
\hline $\begin{array}{l}\text { carnivore } \\
\text { parent } \\
\text { gift } \\
\text { target } \\
\text { passenger } \\
\text { weapon } \\
\text { friend } \\
\text { twin }\end{array}$ & $\begin{array}{l}\text { cause } \\
\text { incite } \\
\text { prevent } \\
\text { prohibit } \\
\text { engender } \\
\text { inverse } \\
\text { converse } \\
\text { identical }\end{array}$ & $\begin{array}{l}\text { forget } \\
\text { expect } \\
\text { remember } \\
\text { intend } \\
\text { persuade } \\
\text { deny } \\
\text { confiscate } \\
\text { borrow } \\
\text { withdraw } \\
\text { distribute }\end{array}$ \\
\hline
\end{tabular}

and utility of relational language. Many of these terms are acquired in childhood, although not necessarily with their full relational meanings.

To preview the approach, we suggest that much of children's learning prowess stems from carrying out comparisons that yield abstractions. Some of these comparisons are grounded in the child's own experience, as when infants repeat an interesting event over and over in the circular reactions noted by Piaget (1952). Other comparisons are culturally invited, either explicitly by the child's caretakers (e.g., "Look-see how the hawk looks like the eagle?") or implicitly by the fact that two situations have a common linguistic label (e.g., "These are both houses"). These early comparisons are typically based on close, concrete similarity. Later, comparisons among less obviously similar exemplars promote further inferences and abstractions. We suggest that comparison is not a low-level feature generalization mechanism, but a process of structural alignment and mapping that is powerful enough to acquire structured knowledge and rules (Gentner \& Medina, 1998; Gentner \& Wolff, 2000).

The plan of the chapter is as follows. We first discuss evidence that analogical learning processes can foster the acquisition of abstract relational 
knowledge. We then examine two ways to invite the comparison process: physical juxtaposition, that is, the direct observation of two comparable exemplars; and symbolic juxtaposition, that is, applying common language to two situations. The former is what we typically discuss in the course of studying analogical processing. Yet we think the latter is fundamentally important as well. We present evidence that language both invites specific comparisons and reifies the resulting abstractions. We begin by discussing structure-mapping as a learning process, and then turn to the role of relational language in furthering this process.

\section{Comparison as Structural Alignment and Mapping}

According to structure-mapping theory, the comparison process is one of alignment and mapping between structured conceptual representations (Falkenhainer, Forbus, \& Gentner, 1989; Gentner, 1983, 1989; Gentner \& Markman, 1994, 1997; Goldstone, 1994; Goldstone \& Medin, 1994; Markman \& Gentner, 1990, 1993, 1996; Medin, Goldstone, \& Gentner, 1993). The commonalities and differences between two situations are found by determining the maximal structurally consistent alignment between their representations. A structurally consistent alignment is characterized by one-to-one mapping (i.e., an element in one representation can correspond to at most one element in the other representation) and parallel connectivity (i.e., if elements correspond across the two representations, then the elements they govern must correspond as well). When more than one structurally consistent match exists between two representations, contextual relevance and the relative systematicity of the competing interpretations are used. All else being equal, the richest and deepest relational match is preferred (the systematicity principle). An important psychological assumption-particularly if one hopes to model learning in childrenis that achieving a deep structural alignment does not require advance knowledge of the point of the comparison. (If it did, it would be relatively useless as a developmental learning process.) Structural alignment can be accomplished with a process that begins blind and local.

We briefly describe a computer model of structure-mapping theory, the Structure-mapping Engine (SME), to give the flavor of this local-to-global alignment process (Falkenhainer, Forbus, \& Gentner, 1989; Forbus, Gentner, \& Law, 1995). When given two representations to align, SME begins blindly with a set of local, mutually inconsistent matches and gradually coalescences these into one or a few deep, structurally consistent alignments.

SME carries out its mapping in three stages. In the first stage, it proposes matches between all identical predicates at any level (attribute, func- 
tion, relation, higher order relation, etc.) between the two representations. At this stage, there are typically many mutually inconsistent $(l \rightarrow n)$ matches. In the second phase, these local matches are coalesced into small, structurally consistent connected clusters (called kernels). Finally, in the third stage these kernels are merged into one or a few maximal structurally consistent interpretations (i.e., mappings displaying one-toone correspondences and parallel connectivity). SME then produces a structural evaluation of the interpretation(s), using a cascade-like algorithm in which evidence is passed down from predicates to their arguments. This method is used because it favors deep systems over shallow systems, even if they have equal numbers of matches (Forbus \& Gentner, 1989). Finally, predicates connected to the common structure in the base, but not initially present in the target, are proposed as candidate inferences in the target. This means that structural completion can lead to spontaneous unplanned inferences. Thus, the process begins with local matches, allowing the interpretation to emerge from the commonalities. But the final interpretation of a comparison is a global match that preserves large-scale structures.

This process model has important implications for the process of comparison in learning and development. First, because matches at all levels enter into the maximal alignment, the easiest and most inevitably noticed similarity comparisons should be those of rich overall (literal) similarity. Indeed, a concrete match like (1) and (2), in which both the objects and the relations match, is intuitively easier to process than an abstract match like (1) and (3), or yet more challenging, (1) and (4):

1. The mother Husky licks her puppies.

2. The mother wolf licks her cubs.

3. The mother falcon grooms her chicks.

4. Best Rubber Company nurtures its spinoffs.

For pairs like (1) and (2), the comparison process runs off easily, because the matches are mutually supporting, yielding one clear dominant interpretation. There is considerable evidence that novice learners and children can perceive overall similarity matches before they perceive purely analogical matches. There is also evidence that adults process concrete matches faster than purely relational matches (Kurtz \& Gentner, 1998) and high-similarity matches faster than low-similarity matches (Wolff \& Gentner, 2000). Further, there is evidence that rich concrete matches, such as two identical dachshunds, are perceived as more similar than sparse concrete matches, such as two identical circles (Gentner \& Rattermann, 1991). 


\section{Comparison Can Promote Learning}

On this account, there are at least four ways in which the process of comparison can further the acquisition of knowledge: (a) highlighting and schema abstraction-extracting common systems from representations, thereby promoting the disembedding of subtle and possibly important commonalities (including common relational systems); (b) projection of candidate inferences-inviting inferences from one item to the other; (c) re-representation-altering one or both representations so as to improve the match (and thereby, as an important side effect, promoting representational uniformity); and (d) re-structuring-altering the domain structure of one domain in terms of the other (Gentner \& Wolff, 2000; Gentner, Brem, Ferguson, Markman, Levidow, Wolff, \& Forbus, 1997). These processes enable the child to learn abstract commonalities and to make relational inferences.

Alignment and Abstraction. Highlighting commonalities may seem like a rather trivial learning process, but this is not true in the case of common relations. Here we present evidence to make the case for the importance of relational highlighting. SME's alignment process, taken as a model of human processing, suggests that the act of carrying out a comparison promotes structural alignment and renders the common structure more salient (Gentner \& Wolff, 1997, 2000; Gick \& Holyoak, 1983; Markman \& Gentner, 1993; Wolff \& Gentner, 2000). We have found considerable evidence that mutual alignment promotes learning and transfer. That is, when a learner is induced to compare two things-for whatever reason, be it common labels, perceptual similarity, or similar roles in pretend play-the alignment process renders the common relational structure more salient and prompts their re-representation at a more abstract level (Gentner, Rattermann, Markman, \& Kotovsky, 1995; Gick \& Holyoak, 1983; Kotovsky \& Gentner, 1996; Loewenstein, Thompson, \& Gentner, 1999; Thompson, Gentner, \& Loewenstein, 2000).

In one set of experiments, we studied the effect of making comparisons on 3-year-olds' ability to perform mapping tasks (Loewenstein \& Gentner, 2001). We used a version of the classic spatial mapping task developed by DeLoache and her colleagues (DeLoache, 1987, 1989, 1995; Uttal, Shreiber, \& DeLoache, 1995). Children were tested on their ability to find a hidden toy in a model room after being shown the location of an identical toy in an analogous model room. The task was deliberately made fairly difficult. First, the "Hiding room" and the "Finding room" were perceptually different: That is, although the objects in the Hiding and Finding rooms belonged to the same categories, they were different in shape and color. Such perceptual differences between the corresponding objects 
make the mapping task more difficult for children (DeLoache, Kolstad, \& Anderson, 1991; Gentner \& Toupin, 1986). Second, the Hiding and Finding rooms each contained not only unique objects-a bed, a desk, and a rug-but also two identical "twin" stools (after Blades \& Cooke, 1994). These twin objects made the task more challenging, because such mappings cannot be accomplished purely by matching objects: Children must also attend to spatial relational information to disambiguate the matches. This twin manipulation is particularly informative because it allows us to tell whether children can surpass the typical initial strategy of simply matching objects (Blades \& Cooke, 1994; Gentner, 1988; Gentner \& Rattermann, 1991; Halford, 1987). To succeed at this mapping task-particularly at mapping between the twin objects-children must note relational correspondences as well as object matches.

The basic procedure was similar to the DeLoache $(1987,1995)$ standard task. Children aged either 36 months or 42 months played a hiding and finding game in which the experimenter hid a toy in the Hiding room while the child watched. The experimenter explained that the child could find a similar toy in the same place in the Finding room. Before beginning this task, the children were divided into two groups that received different pre-task experiences. The comparison group received a brief introductory experience in which children saw the Hiding room, with another virtually identical room (the Hiding2 room) next to it. The only difference between these rooms was the color of the walls and furniture. The experimenter said "Do you see how these are the same? Let's see how these are the same." He then pointed to an object in the Hiding2 room, and asked the child to point to "the one in the very same place" in the Hiding room. The experimenter and the child went through all the objects in the room in this fashion. ${ }^{1}$ The experimenter then removed the Hiding2 room and brought out the Finding room, and began the standard hide-and-find task just described.

The second group was the baseline control group, which was not given a pre-task comparison experience. However, to equate the amount of time children were given to study the Hiding room, we asked the control children to tell us the functions of all the objects in the Hiding room (or, in another study, the colors of all the objects).

Once the pre-task experience was completed, the experimenter brought out the Finding room. Both groups were then given the same search task. As predicted, comparing highly similar examples helped children in the subsequent mapping task. Children in the comparison condition (.77) performed better than children in the control condition

\footnotetext{
'The experimenter was careful not to say the names of any of the objects, because in other studies we have observed that this can improve performance.
} 
(.56). ${ }^{2}$ As already noted, a key test of whether mutual alignment via comparison processing promotes relational understanding is whether it improves performance on the twin items, which require matching both objects and spatial relations. Indeed, children in the comparison group (.69) performed better on the twin items than those in the control group (.44). We conclude that making a concrete comparison gave children insight into relational structure. Even though the two Hiding rooms compared were virtually identical, aligning their representations led children to a better grasp of their common spatial relational schema, which could then be applied to the Finding room.

The benefits of close concrete comparison found here are strikingly different from the traditional view of analogical insight, which centers on "far analogies" between cases that share relational content but not surface similarity. Yet we have repeatedly found benefits of close comparisons. In studies of word learning, Gentner and Namy (1999; Namy \& Gentner, in press) found that 4-year-olds extended new words on the basis of perceptual commonalities if presented with a single standard. However, when children compared two highly similar standards, they were far more likely to extend according to taxonomic categories. In sum, comparing two items promotes noticing common causal and functional relational structure.

The Power of Comparison in Promoting Inductive Inferences. So far we have discussed mutual alignment: learning by comparing two situations and abstracting their commonalities. Children also learn by mapping from well-understood systems to less understood systems, as shown, for example, in studies on children's understanding of biological properties. When young children are asked to make predictions about the behavior of animals and plants, they often invoke analogies with people (Carey, 1985b; Inagaki, 1989, 1990; Inagaki \& Hatano, 1987, 1991; Inagaki \& Sugiyama, 1988; see Rips, 1975, for findings with adults). For example, when asked if they could keep a baby rabbit small and cute forever, 5- to 6year-olds often made explicit analogies to humans: for example, "We can't keep it [the rabbit] forever in the same size. Because, like me, if I were a rabbit, I would be 5 years old and become bigger and bigger." Inagaki and Hatano (1987) noted that this use of the human analogy was not mere "childhood animism" but a rather selective way of mapping from the known to the unknown. That children reason from the species they know best-humans-to other animals follows from the general phenomenology of analogy: A familiar base domain, whose causal structure is well understood, is used to make predictions about a less-well understood target

\footnotetext{
${ }^{2}$ Children's scores are the proportion of times their first finding attempt was correct over the four search trials (two on unique and two on twin items).
} 
(Bowdle \& Gentner, 1997; Gentner, 1983; Holyoak \& Thagard, 1995). For example, knowledge about the solar system was used to make predictions about the atom in Rutherford's (1906) analogy (Gentner, 1983).

Based on what we have said about analogical processing, we might expect children's spontaneous comparisons to be initially constrained by perceptual similarity between base and target, but to become increasingly independent of surface features with increasing knowledge of the target domain. Indeed, examples from studies of biology seem to show this developmental progression. For example, children are more likely to use the analogy to humans the more similar the target entity is to humans (see also Carey, 1985b). There are two reasons to expect this similarity effect. First, high similarity promotes memory retrieval; children are likely to be reminded of creatures similar to the one they are reasoning about. Second, once both items are present, high similarity facilitates the process of alignment and mapping of inferences. In structure-mapping, because the alignment process occurs first and the projection of inferences second, the inferences that are drawn depend on the target as well as the base-specifically, on which system(s) of beliefs the target shares with the base (e.g., Clement \& Gentner, 1991). Additionally, an inferential verification process acts to reject candidate inferences that are inconsistent with what is known about the target. Here the psychological advantages of high similarity go hand in hand with a reasoning advantage: Perceptual similarity is a fairly reliable indicator of biological proximity, such that perceptually similar species are likely to share structural features. Thus high similarity comparisons are more likely to yield valid inferences, that is, inferences that fit with the systematic causal structure of the target.

One alternative to the analogy-based account is the possibility that children's use of humans as their base for stems from a (possibly innate) category organization in which humans are the core members of their biological domain. Such an account might be consistent with theories that posit that children are innately endowed with an understanding of fundamental domains such as biology (e.g., Keil, 1994; Simon \& Keil, 1995). However, Inagaki (1990) provided evidence for the analogy account in an ingenious study. She contrasted the inferential abilities of 5-year-olds who were raising goldfish with those who were not. On the analogy account, goldfishraising children should be able to use their rich causal knowledge of goldfish as a source of analogical reasoning about other animals, even though no one would offer goldfish as the core animal species for our theory of biology. Inagaki's study revealed that goldfish-raising children drew inferences from goldfish to other unfamiliar animals, such as frogs. That is, they used goldfish as an analogical base for reasoning about less familiar animals. Further, goldfish-raising children not only used the goldfish analogy more often for frogs than the non-raisers, but also generated nearly 
twice as many uses of the person analogy for the frog as the non-raisers. Inagaki suggested that in the course of observing and tending goldfish, the goldfish-raisers derived some understanding of the underlying commonalities between goldfish and humans. This abstract perception paved the way for seeing commonalities between the humans and a frog, despite their surface dissimilarities. This is consistent with our earlier proposal of progressive alignment. An alignment and mapping between two kinds of animals promotes further alignments with still other animals.

As Piaget (1951) pointed out, young children often invoke personification analogies in their reasoning. Inagaki and Hatano's $(1987,1991)$ findings suggest that these analogies are not a sign of faulty logic, but rather are a means "to generate an educated guess about less familiar, nonhuman objects" (1987, p. 1020). Of course, animistic analogies (like other analogies) can lead to wrong conclusions, as when children believe a river flows because it wants to get to the sea (Piaget, 1951). But they stem from a highly sensible reasoning strategy, the same strategy used by adults in cases of incomplete knowledge. Inagaki argued that analogical reasoning is not restricted to special cases of inference concerning unfamiliar properties and situations, but, rather, that it is an integral part of the process of knowledge acquisition. Indeed, as the findings of Inagaki and Hatano suggest the process of analogical comparison and abstraction may itself drive the acquisition of abstract knowledge (Gentner \& Medina, 1997, 1998). Analogy plays a formative role in acquisition of knowledge when a well-structured domain provides the scaffolding for the acquisition of a new domain.

\section{The Career of Similarity}

If, as we have argued, analogy and comparison in general are important in children's learning, then how does analogy develop? The progression found in biology mentioned earlier appears to be part of a general trend. Gentner and Rattermann (1991) reviewed a large set of studies and proposed the following account of the career of similarity. In the first stage, young infants respond to overall (literal) similarity and identity: For example, infants show memory for a prior experience with a mobile (by kicking in the same way to make it move) but only if there is a very close perceptual match with the original (Rovee-Collier \& Fagan, 1981). The early stages appear governed by "global" or "holistic" similarity (Smith, 1989, 1993; see also Foard \& Kemler-Nelson, 1984); infants can reliably make overall matches before they can reliably make partial matches. The earliest reliable partial matches are based on direct resemblances between objects, such as the similarity between a round red ball and a round red apple. With increasing knowledge, children come to make pure attribute matches (e.g., a red ball and a red barn) and relational similarity matches (e.g., a ball rolling on a table and a toy car rolling on the floor.) As an ex- 
ample of this developmental progression, when asked to interpret the metaphor $A$ tape recorder is like a camera, 6 -year-olds produced object-based interpretations (e.g., Both are black), whereas 9-year-olds and adults produced chiefly relational interpretations (e.g., Both can record something for later) (Gentner, 1988). Similarly, Billow (1975) reported that metaphors based on object similarity could be correctly interpreted by children of about 5 or 6 years of age, but that relational metaphors were not correctly interpreted until around 10 to 13 years of age.

The conservativeness of initial similarity processing shows up not only in direct interpretation of similarity statements but also in the way similarity is used in learning and transfer. Whereas older children are able to detect the underlying structure shared by analogous problems, younger children tend to need surface commonalities to transfer solution strategies across different problems (e.g. Chen \& Daehler, 1989; Gentner \& Toupin, 1986), or explicit hints about the usefulness of prior problems (Brown, 1989). For example, Baillargeon has found that even young infants can use comparison to perform a rudimentary kind of inferential mapping as a habituation task, however, at 4 months of age, they can do this only under conditions of near identity (Baillargeon, 1991; Baillargeon, Spelke, \& Wasserman, 1985; see Gentner \& Rattermann, 1991, for a summary). That is, they are more likely to (correctly) show surprise at an impossible "box crushing" event if another box of the same size and shape is placed next to the to-be-crushed box, but only if the "calibration" box (which remains visible throughout the event) is identical or highly similar to the box behind the screen. For example, given a visible box that was red with white dots, the 4-month-olds could successfully make the mapping (and thus show surprise) if the "crushed" box behind the screen was red with green dots, but not if it was yellow with green dots or yellow with a clown face. This finding suggests that the babies are doing a kind of similarity-based mapping, using the box that is visible to infer (or remember) the size of the occluded box as it disappears behind the crushing screen. What is striking is the conservativeness of the process. The babies appear to require a strong overall similarity match before they can make the match. Results like these bring home the magnitude of the human achievement in acquiring the kind of flexible, purely relational similarity capability that adults take for granted.

However, there is evidence that more abstract transfer can be induced during infancy for highly familiar relations such as containment (Kolstad \& Baillargeon, 1991). For example, Chen, Sanchez, and Campbell (1997) found that 10-month-old infants could learn to pull on a cloth to reach a toy; but they failed to transfer to a new situation unless the new pulling situation was highly similar to the previously experienced situation. By 13 months, infants were able to transfer with less concrete similarity. Brown 
and her colleagues (Brown, 1989, 1990; Brown \& Kane, 1988) have demonstrated that young children's success in analogical transfer tasks increases when the domains are familiar to them and they are given training in the relevant relations.

In addition to familiarity effects, an indirect argument for the claim that the relational shift is driven by gains in knowledge is that similar patterns are observed in the adult transition from novice to expert. Although people often rely on previously learned examples in problem-solving tasks (e.g., Pirolli \& Anderson, 1985; Ross, 1987), novices often fail to retrieve relevant knowledge (e.g., Brown \& Campione, 1985; Gentner, Rattermann, \& Forbus, 1993; Gick \& Holyoak, 1980, 1983; Novick, 1988; Ross, 1987, 1989; see Reeves \& Weisberg, 1994, for a review). These transfer difficulties are manifested in what has been called the inert knowledge problem-that learners fail to be reminded of prior relevant cases; and the surface similarity problem-that learners are often reminded of prior cases with similar objects and entities but dissimilar relational principles.

With increasing expertise, learners shift from reliance on surface similarities to greater use of structural commonalities in problem solving and transfer (Chi, Feltovich, \& Glaser, 1981). Novick (1988) showed that more advanced mathematics students were more likely to be reminded of structurally similar problems than were novices. Further, when the experts were initially reminded of a surface-similar problem, they were able to reject it quickly. In summation, novices appear to encode domains largely in terms of surface properties, whereas experts possess relationally rich knowledge representations. We speculate that experts tend to develop uniform relational representations (Forbus, Gentner, \& Law, 1995; Gentner \& Rattermann, 1991). On this account, expertise leads to a greater probability that two situations embodying the same principle will be encoded in like terms, and therefore will participate in mutual reminding.

The parallels between cognitive development and adult domain learning add support to the idea that the relational shift is at least partly a novice-expert shift, that is, that the shift is driven by changes in knowledge (Brown, 1989; Gentner \& Rattermann, 1991; Gentner \& Toupin, 1986; Goswami, 1992; Vosniadou, 1989). (However, the alternative explanation of a global and/or maturational change in processing capacity has also been defended [Halford, 1987, 1993].) Evidence for the knowledgechange view comes in three varieties: (a) the relational shift occurs at different ages for different domains and tasks; (b) in particular, even very young children can show considerable analogical ability in highly familiar domains; and (c) children's analogical performance can be improved substantially by providing them with additional relational knowledge.

Our focus on domain-specific advances in knowledge that drive advances in reasoning discards Piaget's global stage theory in favor of a do- 
main-centered view of cognitive development (see also Carey, 1985a). This might seem to leave us with a piecemeal account, one that lacks any link between, for example, children's understanding of conservation of volume and their insight into conservation of weight. We speculate that analogy provides that link. The child who has caught on to conservation in prior domain is more likely to learn the principle in the next domain, and once two domains are grasped, the way is paved for the next (just as the child in Inagaki's studies who has drawn an analogy between goldfish and humans is more likely to see a further mapping to frogs). For example, Gelman (1969) taught 5-year-olds, who initially failed to conserve length, number, mass, and liquid, a discrimination learning task with length and number. Their subsequent conservation performance was near perfect on length and number. More importantly, the children also improved substantially on conservation of the two nontrained quantities, mass and liquid amount. In another study, Gelman (1982) taught children conservation of small numbers and found that they subsequently improved their performance on tasks involving conservation of large numbers. In a similar vein, Simon and Klahr (1995) suggested that an understanding of discrete numbers provides the basis for learning to reason about continuous quantities.

All these findings suggest the operation of analogical mapping within and between domains. Such a process could explain the décalage pattern found across domains in conservation studies. Having acquired conservation early in certain domains (perhaps because of their familiarity and transparency), children then come to perceive analogies to other domains.

We are suggesting that one way in which children and other novices improve their ability to detect powerful analogical matches is through comparison itself. In the next section, we provide evidence for the claim of progressive abstraction: Specifically, we show that experiencing concrete comparisons can promote noticing further more abstract analogies based on the same common structure. We suggest that there is a kind of mutual promotion cycle whereby analogy and similarity act to increase representational uniformity (through re-representation to increase alignment), and are in turn promoted by uniform representations (because the more alignable the representations, the more likely it is that the likeness will be noticed and the comparison made). This positive feedback cycle contributes to the systematization of knowledge, to the gradual replacement of the idiosyncratic perceptions of childhood by the sturdy, relatively uniform representations of the adult cultural world view ${ }^{3}$ (Gentner \& Medina, 1997, 1998; Gentner \& Rattermann, 1991).

\footnotetext{
${ }^{3}$ One could view this evolution as the loss of the brilliant, richly embedded images of childhood in favor of the colorless regimentation of adulthood; uniform relational representation has its price.
} 


\section{What Prompts Learners to Engage in Comparison?}

If comparison is so useful in development, then how does it come about? One simple way is via physical juxtaposition of similar items. A friendly mentor might increase the chances by asking questions that invite the child to compare the two things, as we did in the model-room task described earlier. But a second way to invite comparison is to give two things the same name-what Gentner and Medina (1998) referred to as symbolic juxtaposition. We turn to closely linked cases of physical and symbolic juxtaposition.

Juxtaposition of Similar Examples. Kotovsky and Gentner (1996) showed that experience with concrete similarity comparisons can improve children's ability to detect more abstract similarity. Specifically, 4-yearolds were given a similarity matching task using simple patterns, for example, small and large circles in a symmetric pattern (i.e., oOo). They had to choose which of two other triads this pattern was more similar to. Both alternatives had the same objects ( $\mathrm{xXx}$ or $\mathrm{xxX})$, but only one matched the original in terms of its relations among the objects. When the matches were across dimensions (e.g., small-large-small to light-dark-light), 4year-olds performed at chance levels. However, children's ability to perceive cross-dimensional matches was markedly better when the crossdimensional triads were presented after the within-dimension triads (blocks of size symmetry and blocks of color symmetry) than if the crossdimension and same dimension triads were mixed together. The manipulation that led to this gain was extremely subtle. Both groups of children received the same triads, half within-dimension and half cross-dimension, and performed the same task of choosing the best match to the standard. No feedback was given to either group. Thus the results may be viewed as reflecting the effects of learning from concerted experience.

Why did the order of examples matter so much? Kotovsky and Gentner (1996) suggested a progressive alignment process that occurs when alignable exemplars of the same relational structure are presented together. The within-dimension comparisons, being strong overall matches, are easy to align-they align themselves, virtually without effort on the part of the child (as evidenced by children's high performance on these matches). Each time such an alignment occurs, the common structure is highlighted. This repeated experience on the within-dimension pairs acts to make the higher order relation of symmetry (or monotonicity, another pattern tested) more salient. Children who had received the blocked triads were therefore better able than children in the mixed condition to detect the common higher order structure in the cross-dimensional pairs. Making concrete comparisons improved children's ability to see relational similarities. In short, close alignments can potentiate far alignments. 
These kinds of results are perhaps surprising. It might have been supposed that comparing highly similar examples would lead to the formation of a narrow understanding. Instead, comparison appears to have led to noticing relational commonalities that could then be used in a more abstract mapping. There are three points to be made here. First, what seems like close concrete similarity to an adult may function as an informative analogy to a child. High-similarity examples have the advantage for children that at least some of their correspondences are likely to be obvious, and these may invite more subtle correspondences. The second point is that similarity processing is inherently engaging. Children play matching games for fun, and at any age our attention can be captured when a spontaneous noticing of similarity leads to a flood of further commonalities. Third, because comparison processing tends to promote relational information, it can be revealing even for adults dealing with familiar topics, because relational information tends to be implicit and difficult to call forth within individual items (Gentner \& Clement, 1988). In summation, comparison can provide a naturalistic experiential route by which children come to appreciate relational commonalities.

Symbolic Juxtaposition Through Common Language. If experiential juxtapositions were the sole source of analogical comparisons, learning would proceed very slowly. Even allowing for the fact that children seek out and enjoy repetition-with-variation, and for parents who artfully arrange for the child to encounter informative comparisons, the rate of purely experiential learning would fall well short of children's prodigious pace. Fortunately, we suggest, there is another way to promote comparison: symbolic juxtaposition through common language.

A further study by Kotovsky and Gentner (1996) provided some hints in this direction. Before engaging in the similarity task, 4-year-olds were given labels for higher order relations among the pictured objects (e.g., "even" for symmetry). They then received a categorization task (with feedback) in which they had to give the "picky walrus" only cards that showed "even." The same technique was used for "more and more" (for monotonic increase). After this training, children who succeeded in the labeling task scored well above chance in the cross-dimensional trials (72\% relational responding), as opposed to the chance performance (about 50\%) that children showed with no such training. As with the physical juxtaposition studies, the use of relational labels increased children's attention to common relational structure. This language effect provides the beginnings of a larger claim: The acquisition of relational language influences the development of relational thought. 


\section{Relational Language and Relational Thought}

The suggestion that language might influence cognition is a contentious claim. The ideas of Vygotsky (1962), Sapir (1949), and Whorf (1956), once ardently embraced, have been even more ardently rejected. In recent times, a number of brilliant and influential thinkers have lined up against the position, some on empirical grounds (e.g., Li \& Gleitman, 1999) and some on theoretical grounds (e.g., Fodor, 1975; Pinker, 1994). We return to these challenges later. For now, we briefly summarize the existing theories of how language might influence conceptual life ${ }^{4}$ and then present our own account (see Devitt \& Sterelny, 1987, pp. 172-221, Gumperz \& Levinson, 1996, pp. 1-13, and Lucy, 1992, for useful discussions).

The Sapir-Whorf linguistic relativity hypothesis can be stated as follows:

We dissect nature along lines laid down by our native language. The categories and types that we isolate from the world of phenomena we do not find there because they stare every observer in the face; on the contrary, the world is presented in a kaleidoscope flux of impressions which has to be organized by our minds - and this means largely by the linguistic systems of our minds. (Whorf, 1956, p. 213)

Three central claims constitute the Sapir-Whorf hypothesis as it has been construed in empirical psycholinguistics: (a) languages vary in their semantic partitioning of the world; (b) the structure of one's language influences the manner in which one perceives and understands the environment; (c) therefore, speakers of different languages should have at least partly incommensurable world views. Efforts to demonstrate the strong version of the Whorfian position mostly have failed to produce positive results (see Clark \& Clark, 1977; and Pinker, 1994; however, see Hunt \& Agnoli, 1991; Kay \& Kempton, 1984; and Lucy \& Schweder, 1979, for evidence on the positive side).

Vygotsky's (1962) theory also gives language a major role in cognition. However, his theory focuses chiefly on the general effects of learning a language, rather than on the specific conceptual construals invited by a given language. According to Vygotsky, with the advent of language children augment their pre-linguistic cognitive capabilities of reactive attention, associative learning, and sensorimotor intelligence with post-linguistic capabilities: focused attention, deliberate memory, and symbolic thought (see also Dennett, 1993). According to Vygotsky, acquiring a lan-

${ }^{4}$ This hypothesis has antecedents in the work of Wilhelm von Humboldt (1836, translated 1988), as well as in some aspects of French structuralism, such as the Saussurean idea that a linguistic term derives its value from its relations to all other terms, rather than directly from referential relations to the world. 
guage gives the child control over his own mental processes: the ability to guide his thinking, to direct attention, and to formulate mental plans: "... learning to direct one's own mental processes with the aid of words or signs is an integral part of the process of concept formation" (Vygotsky, 1962, p. 59; quoted in Kuczaj, Borys, \& Jones, 1989).

Thus the Sapir-Whorf view has it that the grammatical structure of a language shapes its speakers' perception of the world, and the Vygotskian view, that possessing a symbol system permits one to direct one's own mental processes. We are suggesting a third position: that learning specific relational terms and systems is important in the development of abstract thought (Gentner \& Rattermann, 1991; Gentner, Rattermann, Markman, \& Kotovsky, 1995; Kotovsky \& Gentner, 1996).

We suggest that relational language provides tools for extracting and formulating abstractions. In particular, we focus on the role of relational labels in promoting the ability to perceive relations, to transfer relational patterns, and to reason about relations. Even within a single language, the acquisition of relational terms provides both an invitation and a means for the learner to modify her thought. When applied across a set of cases, relational labels prompt children to make comparisons and to store the relational meanings that result (Gentner, 1982; Gentner \& Medina, 1997, 1998). In short, relational labels invite the child to notice, represent, and retain structural patterns of elements.

In seeking empirical evidence for this claim, we have focused on spatial relations like on, in, and under (Loewenstein \& Gentner, 1998, in preparation) and symmetry and monotonicity (Kotovsky \& Gentner, 1996; Rattermann \& Gentner, 1998, submitted). These kinds of spatial terms satisfy three criteria for an arena in which to investigate possible effects of language on cognitive development: (a) they show substantial cross-linguistic variation; (b) they lend themselves to objective testing; and (c) they are accessible to children. The logic of these studies is first, to establish a challenging spatial relational task, and then to test whether language for spatial relations can improve children's performance.

Labeling Spatial Patterns Among Entities. Rattermann and Gentner (1998, submitted; Gentner \& Rattermann, 1991) investigated the power of common relational labels to promote relational insight. First, Rattermann, Gentner, and DeLoache (1987) designed a simple mapping task to investigate whether preschool children could align a higher order perceptual relational structure. Children aged 3, 4, and 5 saw two triads of objects, the child's set and the experimenter's set, both arranged in monotonically increasing order according to size. As in DeLoache's model studies, noted earlier, the child watched as the experimenter hid a sticker under an object in the experimenter's triad; she was told that she could 
find her sticker by looking "in the same place" in her triad. The correct response was always based on relational similarity: that is, the child was meant to choose the object of the same relative size and relative position. (These two were always correlated.) Children were always shown the correct response after making their guess.

When the two sets were literally similar, as in Fig. 4.1, 3-year-old children readily learned the mapping. But when the objects were shifted to a cross-mapped pattern (in which the object matches were inconsistent with the best relational alignment) (Gentner \& Toupin, 1986), the children had great difficulty, particularly when the objects were rich and detailed. Indeed, in the rich-object cross-mapped versions of the task, 3- and 4-yearold children performed at chance $(32 \%)$ even though they were shown the correct response on every trial (14 trials total).

Having thus established a challenging relational task, Rattermann and Gentner (1998) then investigated whether providing relational language could help children perform this relational alignment. Before children carried out the cross-mapping task, they were provided with a brief training session in which we modeled using the labels Daddy, Mommy, and Baby (or in other studies, big, little, tiny) for both their own and the experimenter's triads. (These family labels are often used spontaneously by pre-

\section{Cross-Mapping Task}
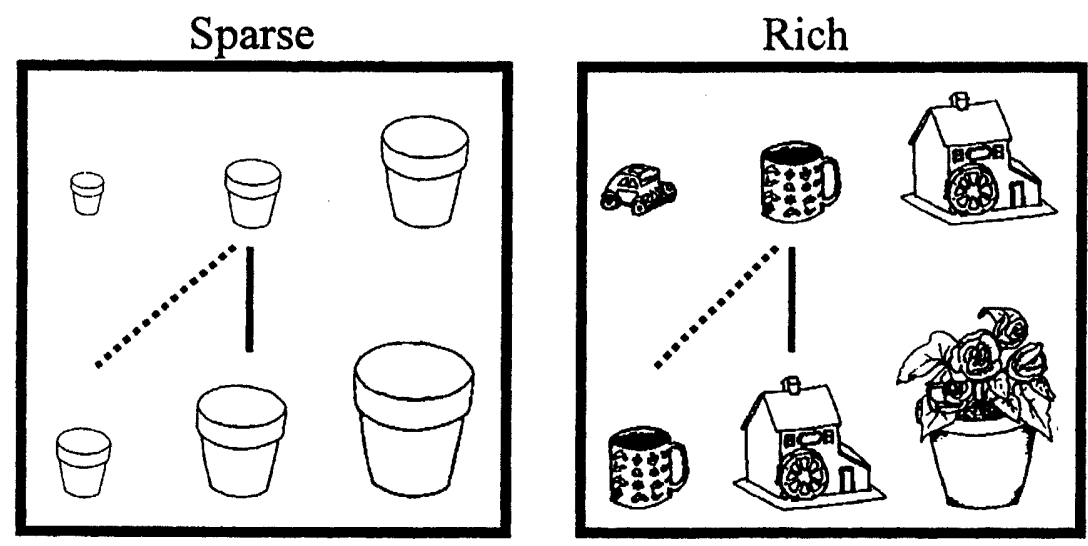

FIG. 4.1. Materials used in the Rattermann and Gentner (1998) crossmapping studies, showing the sparse-object and rich-object conditions. $\mathrm{E}$ labels the experimenter's set; C labels the child's set. Assuming that the sticker is hidden under the experimenter's middle object, the correct relational alternative is the middle object in the child's set; the dashed line shows the (incorrect) object match. 
school children to mark monotonic change [Smith, 1989].) The reasoning was that applying these labels to the three members of each triad would invite the child to highlight the higher order relational pattern of monotonic increase that forms the essential common system to align.

The results of the labeling manipulation were striking. The 3-year-olds performed well in the cross-mapping task on both the sparse (89\% relational responding) and rich (79\% relational responding) stimuli, as compared to performance rates of $54 \%$ and $32 \%$ without relational language correct, respectively. In fact, the 3-year-olds given relational language performed on par with 5-year-olds in the no-language condition. Further, children were fairly well able to transfer their learning to new triads with no further use of the labels by the experimenters. We suggest that the use of common relational labels invited attention to the common relation of monotonic increase and made it possible for the children to carry out a relational alignment. This interpretation is buttressed by the fact that other relational labels denoting monotonic size-change, for example, big, little, tiny, also improved performance, whereas neutral object labels, for example, jiggy, gimli, fantan, did not.

Labeling Spatial Relations Between Figure and Ground. We have also investigated language effects in a spatial mapping task (Loewenstein \& Gentner, 1998, 2001). We focused on a set of spatial terms that children learn early: the spatial prepositions on, in, and under. Children can comprehend and use these prepositions by the time they are 3 years old (Clark, 1974; Johnston, 1988). As in the Rattermann and Gentner studies, we first established a challenging spatial task and then tested whether labeling the relevant spatial relations would lead to successful task performance. We devised a spatial mapping task using two boxes, modeled after Wilcox and Palermo's (1980) neutral object. The box is designed to have three equally salient placement locations (on top, in the middle, and underneath the box in Fig. 4.2). Each box had three identical plastic cards, one in each position. One card had a star on its back, making it the "win-

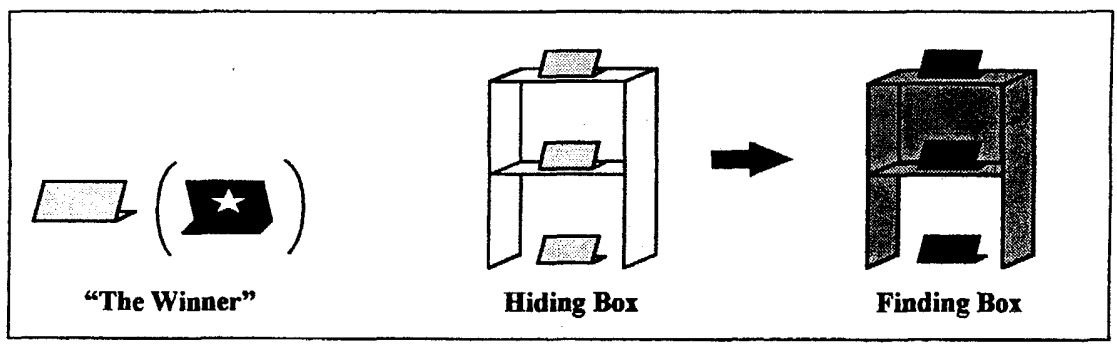

FIG. 4.2. Materials used in the Loewenstein and Gentner (1998) spatial mapping test. 
ner." Children were shown the location of the winner at the Hiding box, and had to find the winner in the corresponding location at the Finding box.

In some respects the task is a relatively easy version of the search task used in DeLoache's $(1987,1995)$ and our own model room studies. The Hiding and Finding models are nearly identical and they are placed close together so that they can be simultaneously viewed. However, in other fundamental respects, the task is more difficult than the standard search tasks. Our task uses only one reference object-the box-and all objects are placed with respect to it. Thus to solve the task the child must attend to the specific spatial relation between the hiding place and the box. Simple object correspondences are not enough.

The key manipulation was made during children's initial training. Children either placed toys as specified by spatial language (Language condition: "Can you put this on the box?"), or placed toys in locations the experimenter pointed to (Control condition: "Can you put this here?"). After performing one of these training exercises, all children performed the same mapping task between the two boxes. We found that 44-month-old Language group children performed better than Control group children on the mapping task, the latter performing at levels just better than chance. Thus, hearing relational language facilitated children's ability to map on the basis of spatial relations.

Summary of Empirical Results. The research summarized here suggests several conclusions. First, it supports the career of similarity thesis: Children begin with highly concrete similarity matches and gradually become able to appreciate selective matches. Second, among partial matches there is a relational shift from early focus on object-based matches to a later ability to perceive purely relational commonalities. Third, this development is driven in large part by changes in domain knowledge. Fourth, one particular kind of knowledge that may be particularly important is the acquisition of relational language.

The findings reviewed are consistent with our claim that children's early representations are conservative and context-specific, relying on massive overlap of perceptual features, and that they gradually develop relationally articulated representations, which enable them to appreciate partial similarity and analogy. We considered two ways of fostering relational insight: first, the progressive alignment of a series of cases so as to reveal common relational structure; and second, the use of relational language to invite the perception of common relations. The first of these represents alignment through experiential juxtaposition; the second, alignment through symbolic juxtaposition. 


\section{DISCUSSION}

We began this chapter by asking "Why are humans so smart?" That is, why is our cognition so much more adaptive and flexible than that of other creatures $?^{5}$ We focused on two contributors to our learning capacities. One of these, our penchant for analogizing and systematizing what we learn, is internal to our cognitive makeup, and one, the possession of a system that includes names for relational terms, arises from social communication systems. We reviewed evidence that comparison processes-not only abstract analogy but also mundane similarity-contribute importantly to children's experiential learning. In particular, we discussed three ways in which alignment and projection-analogical processing-contributes to learning: highlighting due to mutual alignment, inference projection, and re-representation.

We have argued for the career of similarity account of development, a progression from overall similarity to object similarity to higher level relational similarity, and from focusing on perceptual to focusing on conceptual properties. The course of similarity has wide ramifications. Virtually every cognitive process, from categorization to transfer, is influenced by explicit or implicit similarity comparisons. Thus, as similarity comparisons evolve from being initially perceptual and context-bound to becoming increasingly framed in terms of common higher order structure, children's general cognitive abilities show an increasing capacity to notice and reason about abstract situations.

The structural alignment and mapping process grades naturally from highly concrete literal similarity comparisons to purely abstract comparisons. Indeed, we speculate that some of children's learning prowess stems from a particular pattern of initial docile retention followed by comparison and analogical abstraction. Children originally acquire knowledge at a highly specific, conservative level; later, comparisons-initially concrete, but progressively more abstract-among exemplars promote abstraction and rule learning.

Similarity Reconsidered. Similarity is often treated rather slightingly in current theories of cognitive development. It is regarded as a deceiver,

\footnotetext{
${ }^{5}$ Many other species lead us in specific cognitive skills-the nuthatch in memory for multiple locations, the carrier pigeon and several others in navigational abilities, and so on. Nor are we the only generalists; formidable learning capabilities have been demonstrated by crows, parrots, dolphins, and chimpanzees, among others. But we clearly excel in our ability to learn and adapt to varying environments, and (for better or worse) to adapt the environment to ourselves.
} 
a tempting fraud that lures children away from deeper understanding. This suspicion of similarity goes hand in hand with a suspicion of general learning mechanisms. Keil (1994) stated: ". . the extraordinary ease with which all of us do learn about functional objects, such as tools, relative to other species that exhibit sophisticated learning in so many other areas ... argues against reduction to general learning procedures" (p. 251). In contrast, we suggest that learning by analogy and similarity, even mundane within-dimension similarity, can act as a positive force in learning and development. We have argued that the simple process of carrying out similarity and analogy comparisons may play a fundamental role in the development of structured representations.

Further, although we have focused on children's analogical processing, there are other learning mechanisms that contribute to the development of abstract cognition. To name some examples, children learn via explanations (Callanan, 1990, 1991), via questions asked and answered, through dialogues with parents (e.g., Clark, 1993, 2001), by apprenticeship and scaffolded learning (Nunes, Schliemann, \& Carraher, 1993; Rogoff, 1990); by observing successes and failures in goal-driven behavior (Tomasello, 1995), and by imitation (Meltzoff, 1988).

The Role of Language in Cognitive Development. There is abundant evidence for interactions between language and cognition in development (Nelson, 1995). First, children readily learn and extend new words (Markman \& Hutchinson, 1984) and appear to assume that words refer to things of like kind. These patterns of extension may play a role in the development of taxonomic relationships (Byrnes \& Gelman, 1991; Markman, 1989; Waxman \& Gelman, 1986; Waxman \& Hall, 1993: Waxman \& Markow, 1995). Young children's willingness to make inductive inferences between entities is enhanced by the presence of a common label (Davidson \& Gelman, 1990; Gelman, 1989; Gelman \& Markman, 1987).

However, with a few exceptions (Gopnik \& Choi, 1990; Shatz, 1991; Smith \& Sera, 1992; Waxman \& Markow, 1995) most of the previous empirical work on how labels influence categorization has focused on object concepts. Our research asks whether these benefits extend to relational concepts. The results reported here suggest that the answer is yes. Children who experienced the simple linguistic intervention of practicing with relational labels (e.g., Daddy, Mommy, Baby) showed substantially more relational responding than did baseline children. The interpretation is that the use of relational labels can highlight higher order relations (e.g., monotonic increase).

There is also intriguing cross-linguistic evidence that infants swiftly learn their language-specific semantic patterns (Bowerman 1989; Choi \& Bowerman, 1991; Imai \& Gentner, 1997). Although this in itself does not 
imply any influence of language on thought, it sets the stage for further investigations. For example, Gopnik and Choi (1990) have suggested that cross-linguistic semantic differences are associated with corresponding differences in the timing of cognitive achievements. As another example, Lucy (1994) has suggested that the linguistic pattern of numeral classifier languages such as Yucatec Mayan and Japanese, which focus relatively more on substance and less on shape than English, could lead to greater reliance on substance in nonlinguistic tasks. Consistent with this suggestion, adult similarity judgments in Yucatec (Lucy, 1996) and Japanese (Imai \& Mazuka, 1997; see also Imai \& Gentner, 1997, and Gentner \& Boroditsky, 2001) show greater reliance on substance than similar tasks in English.

We conjecture that learning words for relations is crucial to the development of analogy. Throughout this chapter we have emphasized the role of language in inviting symbolic juxtapositions. By giving two things the same name, we invite children to compare them, whether or not they occur in experiential juxtaposition.

Why Relational Language Matters. The prediction that relational language could contribute to higher order cognition is motivated by theoretical considerations about the relative saliency of objects and relations (Gentner, 1981, 1982). Objects are easy to notice; they are learned early, and even adults sometimes are swayed by object matches when relational matches would be more useful. The great value of analogy is in creating a focus on common relational systems-lifting an abstract pattern away from its object arguments. But such insights are often fleeting, and relational terms can preserve them. Relational language is cognitively useful both in promoting relational focus and in suppressing intrusions from objects and object matches. Learned systems of relations provide the child with the representational tools with which to structure knowledge.

To summarize, there are at least four ways in which relational language can foster the ability to retain and use relational patterns:

1. Naming a relational pattern helps to preserve it as a pattern, increasing the likelihood that the learner will perceive the pattern again across different circumstances. This is the effect obtained in our studies of mapping (Gentner \& Rattermann, 1991; Loewenstein \& Gentner, 1998, in preparation; Rattermann \& Gentner, 1998, submitted) and in our similarity task (Kotovsky \& Gentner, 1996).

2. Hearing a relational term used invites children to seek a relational meaning, even when none is initially obvious. Indirect evidence for this claim is the pattern whereby children initially interpret relational terms as object descriptors, and only later come to appreciate the relational mean- 
ing. Similarly, kinship terms may be understood initially in terms of characteristics of individuals, and only later in terms of relational roles (Clark, 1993; Keil \& Batterman, 1984). As another example, Hall and Waxman (1993) found that preschool children (even after being told that a certain doll was a passenger because he was riding on the train) tended to interpret passenger as an object-reference term, and apply it to a similar-looking doll rather than to another doll riding the train; only children who already knew an object-level name for the item were likely to take passenger as a relational term. In a related vein, the full relational meanings of terms such as if and because (Byrnes, 1991; Scholnick \& Wing, 1982) or mix (Gentner, 1978) may be acquired gradually, and may not be fully present until 8 or 9 years of age. Admittedly, these findings demonstrate only that relational meanings are not immediately learned. Nevertheless, we conjecture that hearing relational terms invites the meanings.

3. Using a relational term helps to reify an entire pattern, so that new assertions can be stated about it. That is, a named relational schema can serve as an argument to a higher order proposition. For example, consider the economy made possible by terms like betrayal, loss, revenge, and authority. To express a relatively straightforward causal assertion like "The true cause of Clytemnestra's revenge was not the loss of her child but the betrayal of her authority," or the related counterfactual (e.g., No betrayal, no revenge) would be prohibitively awkward without such relational compaction. As another example of relational embedding, consider Wittgenstein's "Philosophy is a battle against the bewitchment of our intelligence by means of language" (itself, of course, a testimony to the power of language over thought).

4. Habitual use of a given set of relational terms promotes uniform relational encoding, thereby increasing the probability of transfer. As noted earlier, to the extent that a given domain is encoded in terms of a more or less standard set of relational terms, the likelihood of matching new examples with stored knowledge is increased. Relational language can increase the probability of appropriate principle-based transfer and mitigate the classic problems of inert knowledge and surface-based retrieval (Forbus, Gentner, \& Law, 1995).

The fourth claim is perhaps the most speculative. Direct evidence is rather scant, but there are some promising leads. Clement, Mawby, and Giles (1994) gave adults passages to read and later gave them new passages that were structurally similar but differed on the surface, the classic situation in which poor retrieval abilities have been demonstrated (Gentner, Rattermann, \& Forbus, 1993; Gick \& Holyoak, 1980; Ross, 1989). For some learners, the parallel structure in the two matching passages was expressed using relational terms that had the same meanings: $\mathrm{X}$ ate $\mathrm{Y}$ and $\mathrm{A}$ 
consumed B. For others, the parallel structure was expressed using nonsynonymous relational pairs: for example, $\mathrm{X}$ munched on $\mathrm{Y}$ and A gobbled up B. This was a fairly subtle manipulation; the differing relational pairs were partly overlapping in meaning, so that they could readily be aligned if both passages were seen together. However, even this minimal manipulation made a difference: People who received synonymous terms, such as ate and consumed, were more likely to retrieve the initial passage given the probe than those who received the differing pairs. Clement et al. (1994) concluded that the use of common relational labels can promote analogical retrieval in adults. Further afield, gestalt researchers found that a simple labeling manipulation could help subjects to overcome the "functional fixedness" effect (Glucksberg \& Danks, 1968; Glucksberg \& Weisberg, 1966).

In our own research, we have also found evidence that relational language promotes relational transfer. First, in the Rattermann and Gentner mapping task, children who were given relational terminology (e.g., $D a d d y$, Mommy, Baby) performed better than a matched control group not only on the initial mapping task but also on both immediate and delayed transfer tasks without further mention of the labels. Loewenstein and Gentner have found a similar pattern: The benefits of using spatial relational terms appear to persist over time in the box mapping task (Loewenstein \& Gentner, in preparation). We suggest that the relational labels invited an encoding of the higher order relational of monotonic increase, which not only helped the children accomplish the mapping task on the initial occasion, but was retained over time to provide a deeper structural encoding on subsequent occasions (Gentner \& Rattermann, 1991; Kotovsky \& Gentner, 1996; Rattermann \& Gentner, 1998, in preparation).

Language and Thought. The position we are taking here is not identical to either the Sapir-Whorf hypothesis or Vygotsky's theory of language and thought. Without denying other kinds of linguistic influences, our purpose here is to argue that the learning of specific relational terms and relational systems fosters human ability to notice and reason about the corresponding abstractions.

We must be clear about some things we are not claiming. We do not claim (a) that all important concepts are relational; (b) that all abstract concepts are relational; (c) that all relational concepts are linguistically provided; or (d) that we can only reason and analogize about linguistically encapsulated relations. Counterexamples to (a) include important concepts like tiger and banana. Counterexamples to (b) include concepts like mammal and plant. ${ }^{6}$ Counterexamples to (c) are best found by examining

\footnotetext{
${ }^{6}$ It could perhaps be maintained that mammal and plant are in some sense relational but the argument seems strained compared to the clear relationality of, say, carnivore.
} 
cross-linguistic patterns that suggest that some relational concepts are formed prelinguistically, so that their corresponding linguistic terms are particularly easy to acquire (Choi \& Bowerman, 1991). One counterargument to (d) is the existence of mechanisms such as metaphorical abstraction (Bowdle \& Gentner, 1999, in preparation; Glucksberg \& Keysar, 1990) that can allow concrete terms to be extended into abstract relational meanings. Another is the historical development in science, mathematics, or even the Internet, of progressively more higher order relational terms. Clearly, speakers constantly go beyond the current resources of their language to notice new relational commonalities. Our claim is that the set of currently lexicalized existing relations frames the set of new ideas that can be readily noticed and articulated.

Our position can be compared with other recent proposals aimed at achieving a psychologically defensible position on language and thought. Slobin's (1996) "thinking for speaking" view states that language may determine the construal of reality during language use, without necessarily pervading our entire worldview (see also Pinker, 1989, p. 360). Our proposal goes beyond thinking for speaking in that we argue for lasting benefits of language on thought. We have shown that children can retain the conceptual advantages of learning relational terms even when the terms are not overtly used. Our proposal is related to Carey's (1985b) notion of "tools of wide application" (see also Byrnes, 1991; Scholnick \& Hall, 1991). We suggest that relational concepts serve as tools for thought of varying degrees of generality. Our proposal is also related to Gopnik and Meltzoff's $(1987,1997)$ proposal that there is a bidirectional relation between lexical and conceptual achievements. They provide evidence for the simultaneous emergence of lexical and conceptual insights. For example, they suggest an association between the rapid increase in object names during the second year and the onset of the ability to sort objects into basic-level categories, and between using means-ends planning and saying "uh-oh" for an error. Finally, our thesis is consistent with discussions by Nelson (1996) and Tomasello (1999) of language as a means by which culture influences the development of cognition.

Nonetheless, it could be argued that our position is so moderate as to be vacuous or trivial. Pinker refers to " 'weak' versions of the Whorfian hypothesis, namely that words can have some effect on memory or categorization" (Pinker, 1994, p. 65). Devitt and Sterelny (1987) put it more strongly: ". . . the argument for an important linguistic relativity evaporates under scrutiny. The only respect in which language clearly and obviously does influence thought turns out to be rather banal: language provides us with most of our concepts" (p. 178). These concessions hardly seem banal. If language influences categorization and memory-and if indeed language provides us with most of our concepts (a position consider- 
ably beyond what we have claimed)-then its centrality in cognition and cognitive development is beyond dispute.

In summation, we have suggested, first, that structure-mapping processes are a powerful engine of learning in children, and, focusing on relational learning, that a major influence on what to align is relational language. Symbolic comparison operates in tandem with experiential comparison to foster the development of abstract thought. It is fitting here to end with a prescient comment from Piaget (1954): “. . . after speech has been acquired the socialization of thought is revealed by the elaboration of concepts, of relations, and by the formation of rules, that is, there is a structural evolution" (p. 360).

\section{ACKNOWLEDGMENTS}

This research was supported by NSF grant SBR-9720313 and NSF-LIS grant SBR-9511757 to the first author. The development of the computer simulation was supported by ONR contract N-00014-92-J-1098. This chapter was partially prepared while the first author was a Fellow at the Center for Advanced Study in the Behavioral Sciences. We are grateful for the financial support provided by the William T. Grant Foundation, award \#95167795. We thank Ken Forbus, Ken Kurtz, Art Markman, Jose Medina, Mary Jo Rattermann, Phillip Wolff, and the Analogy and Similarity group at Northwestern University for helpful discussions of these issues.

\section{REFERENCES}

Baillargeon, R. (1987). Object permanence in 3.5- and 4.5-month-old infants. Developmental Psychology, 23, 655-664.

Baillargeon, R. (1991). Reasoning about the height and location of a hidden object in 4.5and 6.5-month-old infants. Cognition, 38, 13-42.

Baillargeon, R., Spelke, E. S., \& Wasserman, S. (1985). Object permanence in five-month-old infants. Cognition, 20, 191-208.

Billow, R. M. (1975). A cognitive developmental study of metaphor comprehension. Developmental Psychology, 11, 415-423.

Blades, M., \& Cooke, Z. (1994). Young children's ability to understand a model as a spatial representation. Journal of Genetic Psychology, 155, 201-218.

Bowdle, B., \& Gentner, D. (1997). Informativity and asymmetry in comparisons. Cognitive Psychology, 34(3), 244-286.

Bowdle, B., \& Gentner, D. (1999). Metaphor comprehension: From comparison to categorization. Proceedings of the Twenty-first Annual Meeting of the Cognitive Science Society (pp. 90-95). Vancouver, BC.

Bowdle, B., \& Gentner, D. (submitted). The career of metaphor.

Bowerman, M. (1989). Learning a semantic system: What role do cognitive predispositions play? In M. L. Rice \& R. L. Schiefelbusch (Eds.), The teachability of language. Baltimore: Brooks. 
Brown, A. L. (1989). Analogical learning and transfer: What develops? In S. Vosniadou \& A. Ortony (Eds.), Similarity and analogical reasoning (pp. 369-412). New York: Cambridge University Press.

Brown, A. L. (1990). Domain specific principles affect learning and transfer in children. Cognitive Science, 14, 107-134.

Brown, A. L., \& Campione, J. C. (1985). Three faces of transfer: Implications for early competence, individual differences, and instruction. In M. Lamb, A. Brown, \& B. Rogoff (Eds.), Advances in developmental psychology (Vol. 3, pp. 143-192). Hillsdale, NJ: Lawrence Erlbaum Associates.

Brown A. L., \& Kane, M. J. (1988). Preschool children can learn to transfer: Learning to learn and learning from example. Cognitive Psychology, 20, 493-523.

Byrnes, J. P. (1991). Acquisition and development of if and because: Conceptual and linguistic aspects. In S. A. Gelman \& J. P. Byrnes (Eds.), Perspectives on language and thought: Interrelations in development (pp. 3-27). London: Cambridge University Press.

Byrnes, J. P., \& Gelman, S. A. (1991). Perspectives on thought and language: Traditional and contemporary views. In S. A. Gelman \& J. P. Byrnes (Eds.), Perspectives on language and thought: Interrelations in development (pp. 3-27). London: Cambridge University Press.

Callanan, M. A. (1990). Parents' descriptions of objects: Potential for children's inferences about category principles. Cognitive Development, 5, 101-122.

Callanan, M. A. (1991). Parent-child collaboration in young children's understanding of category hierarchies. In S. A. Gelman \& J. P. Byrnes (Eds.), Perspectives on thought and language: Interrelations in development (pp. 440-484). Cambridge, England: Cambridge University Press.

Carey, S. (1985a). Conceptual change in childhood. Cambridge, MA: MIT Press.

Carey, S. (1985b). Are children fundamentally different kinds of thinkers and learners than adults? In S. F. Chipman, J. W. Segal, \& R. Glaser (Eds.), Thinking and leaming skills: Current research and open questions (Vol. 2, pp. 485-517). Hillsdale, NJ: Lawrence Erlbaum Associates.

Chen, Z., \& Daehler, M. W. (1989). Positive and negative transfer in analogical problem solving by 6-year-old children. Cognitive Development, 4, 327-344.

Chen, Z., Sanchez, R. P., \& Campbell, T. (1997). From beyond to within their grasp: The rudiments of analogical problem solving in 10- and 13-month olds. Developmental Psychology, 33(5), 790-801.

Chi, M. T. H., Feltovich, P. J., \& Glaser, R. (1981). Categorization and representation of physics problems by experts and novices. Cognitive Science, 5, 121-152.

Choi, S., \& Bowerman, M. (1991). Learning to express motion events in English and Korean: The influence of language-specific lexicalization patterns. Cognition, 41, 83-121.

Clark, E. V. (1974). Non-linguistic strategies and the acquisition of word meanings. Cognition, $2,161-182$.

Clark, E. V. (1993). The lexicon in acquisition. Cambridge, England: Cambridge University Press.

Clark, E. V. (2001). Emergent categories in first language acquisition. In M. Bowerman \& S. Levinson (Eds.), Language acquisition and conceptual development. Cambridge, England: Cambridge University Press.

Clark, H. H., \& Clark, E. V. (1977). Psychology and language: An introduction to psycholinguistics (pp. 515-558). New York: Harcourt Brace Jovanovich.

Clement, C. A., \& Gentner, D. (1991). Systematicity as a selection constraint in analogical mapping. Cognitive Science, 15, 89-132.

Clement, C. A., Mawby, R., \& Giles, D. E. (1994). The effects of manifest relational similarity on analog retrieval. Journal of Memory and Language, 33, 396-420.

Davidson, N. S., \& Gelman, S. A. (1990). Inductions from novel categories: The role of language and conceptual structure. Cognitive Development, 5, 151-176. 
DeLoache, J. S. (1987). Rapid change in the symbolic functioning of very young children. Science, 238, 1556-1557.

DeLoache, J. S. (1989). Young children's understanding of the correspondence between a scale model and a larger space. Cognitive Development, 4, 121-139.

DeLoache, J. S. (1995). Early understanding and use of symbols-The model model. Current Directions in Psychological Science, 4(4), 109-113.

DeLoache, J. S., Kolstad, V., \& Anderson, K. N. (1991). Physical similarity and young children's understanding of scale models. Child Development, 62, 111-126.

Dennett, D. C. (1993). Learning and labeling. Mind and Language, 8(4), 540-548.

Devitt, M., \& Sterelny, K. (1987). Language and reality: An introduction to the philosophy of language. Oxford, England: Basil Blackwell.

Falkenhainer, B., Forbus, K. D., \& Gentner, D. (1989). The structure-mapping engine: Algorithm and examples. Artificial Intelligence, 41, 1-63.

Foard, C. F., \& Kemler-Nelson, D. G. (1984). Holistic and analytic modes of processing: The multiple determinants of perceptual analysis. Journal of Experimental Psychology, 113(1), 94-111.

Fodor, J. A. (1975). The language of thought. New York: Random House.

Forbus, K. D., \& Gentner, D. (1989). Structural evaluation of analogies: What counts? Proceedings of the Eleventh Annual Conference of the Cognitive Science Society, 341-348. Hillsdale, NJ: Lawrence Erlbaum Associates.

Forbus, K. D., Gentner, D., \& Law, K. (1995). MAC/FAC: A model of similarity-based retrieval. Cognitive Science, 19, 141-205.

Gelman, R. (1969). Conservation acquisition: A problem of learning to attend to relevant attributes. Journal of Experimental Child Psychology, 7, 167-187.

Gelman, R. (1982). Accessing one-to-one correspondence: Still another paper about conservation. Journal of Psychology, 73, 209-220.

Gelman, R. (1990). First principles organize attention to and learning about relevant data: Number and the animate-inanimate distinction as examples. Cognitive Science, 14, 79-106.

Gelman, R., \& Gallistel, C. R. (1978). The child's understanding of number. Cambridge, MA: Harvard University Press.

Gelman, S. A. (1989). Children's use of categories to guide biological inferences. Human Development, 32, 65-71.

Gelman, S. A., \& Markman, E. M. (1987). Young children's inductions from natural kinds: The role of categories and appearances. Child Development, 58, 1532-1541.

Gentner, D. (1978). On relational meaning: The acquisition of verb meaning. Child Development, 49, 988-998.

Gentner, D. (1982). Why nouns are learned before verbs: Relativity vs. natural partitioning. In S. A. Kuczaj (Ed.), Language development: Syntax and semantics (pp. 301-334). Hillsdale, NJ: Lawrence Erlbaum Associates.

Gentner, D. (1983). Structure-mapping: A theoretical framework for analogy. Cognitive Science, 7, 155-170.

Gentner, D. (1988). Metaphor as structure mapping: The relational shift. Child Development, 59, 47-59.

Gentner, D. (1989). Mechanisms of analogical learning. In S. Vosniadou \& A. Ortony (Eds.), Similarity and analogical reasoning (pp. 199-241). London: Cambridge University Press.

Gentner, D., \& Boroditsky, L. (2001). Individuation, relativity and early word learning. In M. Bowerman \& S. Levinson (Eds.), Language acquisition and conceptual development (pp. 215-256). Cambridge, England: Cambridge University Press.

Gentner, D., Bowdle, B., Wolff, P., \& Boronat, C. (2001). Metaphor is like analogy. In D. Gentner, K. J. Holyoak, \& B. N. Kokinov (Eds.), The analogical mind: Perspectives from cognitive science (pp. 199-253). Cambridge, MA: MIT Press. 
Gentner, D., Brem, S., Ferguson, R., Markman, A., Levidow, B. B., Wolff, P., \& Forbus, K. D. (1997). Analogical reasoning and conceptual change: A case study of Johannes Kepler. The Journal of Learning Sciences, 6(1), 3-40.

Gentner, D., \& Clement, C. (1988). Evidence for relational selectivity in the interpretation of analogy and metaphor. In G. H. Bower (Ed.), The psychology of learning and motivation, advances in research and theory (Vol. 22, pp. 307-358). New York: Academic Press.

Gentner, D., \& Markman, A. B. (1994). Structural alignment in comparison: No difference without similarity. Psychological Science, 5(3), 152-158.

Gentner, D., \& Markman, A. B. (1997). Structure mapping in analogy and similarity. American Psychologist, 52, 45-56.

Gentner, D., \& Medina, J. (1997). Comparison and the development of cognition and language. Cognitive Studies: Bulletin of the Japanese Cognitive Science Society, 4(1), 112-149.

Gentner, D., \& Medina, J. (1998). Similarity and the development of rules. Cognition, 65, 263-297.

Gentner, D., \& Namy, L. L. (1999). Comparison in the development of categories. Cognitive Development, 14, 487-513.

Gentner, D., \& Rattermann, M. J. (1991). Language and the career of similarity. In S. A. Gelman \& J. P. Byrnes (Eds.), Perspectives on language and thought: Interrelations in development (pp. 225-277). London: Cambridge University Press.

Gentner, D., Rattermann, M. J., \& Forbus, K. D. (1993). The roles of similarity in transfer: Separating retrievability and inferential soundness. Cognitive Psychology, 25, 524-575.

Gentner, D., Rattermann, M. J., Markman, A. B., \& Kotovsky, L. (1995). Two forces in the development of relational similarity. In T. J. Simon \& G. S. Halford (Eds.), Developing cognitive competence: New approaches to process modeling (pp. 263-313). Hillsdale, NJ: Lawrence Erlbaum Associates.

Gentner, D., \& Toupin, C. (1986). Systematicity and surface similarity in the development of analogy. Cognitive Science, 10, 277-300.

Gentner, D., \& Wolff, P. (1997). Alignment in the processing of metaphor. Journal of Memory and Language, 37, 331-355.

Gentner, D., \& Wolff, P. (2000). Metaphor and knowledge change. In E. Dietrich \& A. Markman (Eds.), Cognitive dynamics: Conceptual change in humans and machines (pp. 295-342). Mahwah, NJ: Lawrence Erlbaum Associates.

Gick, M. L., \& Holyoak, K. J. (1983). Analogical problem solving. Cognitive Psychology, I2, 306-355.

Gick, M. L., \& Holyoak, K. J. (1983). Schema induction and analogical transfer. Cognitive Psychology, 15, 1-38.

Gleitman, L. R., \& Wanner, E. (1982). Language acquisition: The state of the art. Cambridge, England: Cambridge University Press.

Glucksberg, S., \& Danks, J. H. (1968). Effects of discriminative labels and of nonsense labels upon the availability of novel function. Jourmal of Verbal Learning and Verbal Behavior, 7, 72-76.

Glucksberg, S., \& Keysar, B. (1990). Understanding metaphorical comparisons: Beyond similarity. Psychological Review, 97(1), 3-18.

Glucksberg, S., \& Weisberg, R. W. (1966). Verbal behavior and problem solving: Some effects of labeling in a functional fixedness problem. Journal of Experimental Psychology, 71, 659-664.

Goldstone, R. L. (1994). Similarity, interactive activation, and mapping. Joumal of Experimental Psychology: Learning, Memory, and Cognition, 20(1), 3-28.

Goldstone, R. L., \& Medin, D. L. (1994). Time course of comparison. Journal of Experimental Psychology: Learning, Memory, and Cognition, 20(1), 29-50.

Gopnik, A., \& Choi, S. (1990). Do linguistic differences lead to cognitive differences? A crosslinguistic study of semantic and cognitive development. First Language, 10, 199-215. 
Gopnik, A., \& Meltzoff, A. N. (1987). The development of categorization in the second year and its relation to other cognitive and linguistic developments. Child Development, 58, 1523-1531.

Gopnik, A., \& Meltzoff, A. N. (1997). Words, thoughts, and theories. Cambridge, MA: MIT Press.

Goswami, U. (1992). Analogical reasoning in children. Hillsdale, NJ: Lawrence Erlbaum Associates.

Gumperz, J. J., \& Levinson, S. C. (1996). Rethinking linguistic relativity. Cambridge, England: Cambridge University Press.

Halford, G. S. (1987). A structure-mapping approach to cognitive development. International Journal of Psychology, 22, 609-642.

Halford, G. S. (1993). Children's understanding: The development of mental models. Hillsdale, NJ: Lawrence Erlbaum Associates.

Hall, D. G., \& Waxman, S. R. (1993). Assumptions about word meaning: Individuation and basic-level kinds. Child Development, 64(5), 1550-1570.

Hirschfeld, L. A., \& Gelman, S. A. (Eds.). (1994). Mapping the mind: Domain specificity in cognition and culture. New York: Cambridge University Press.

Holyoak, K. J., \& Thagard, P. (1995). Mental leaps: Analogy in creative thought. Cambridge, MA: MIT Press.

Humboldt, W. von (1988). On language: The diversity of human language-structure and its influence on the mental development of mankind (Peter Heath, Trans.). Cambridge, England: Cambridge University Press. (Original work published 1836).

Hunt, E., \& Agnoli, F. (1991). The Whorfian hypothesis: A cognitive psychology perspective. Psychological Review, 98, 377-389.

Imai, M., \& Gentner, D. (1997). A crosslinguistic study of early word meaning: Universal ontology and linguistic influence. Cognition, 62, 169-200.

Imai, M., \& Mazuka, R. (1997, April). A crosslinguistic study on the construal of individuation in linguistic and non-linguistic contexts. Poster session presented at the Society for Research in Child Development, Washington, DC.

Inagaki, K. (1989). Developmental shift in biological inference processes: From similaritybased to category-based attribution. Human Development, 32, 79-87.

Inagaki, K. (1990). The effects of raising animals on children's biological knowledge. British Journal of Developmental Psychology, 8, 119-129.

Inagaki, K., \& Hatano, G. (1987). Young children's spontaneous personification as analogy. Child Development, 58, 1013-1020.

Inagaki, K., \& Hatano, G. (1991). Constrained person analogy in young children's biological inference. Cognilive Development, 6, 219-231.

Inagaki, K., \& Sugiyama, K. (1988). Attributing human characteristics: Developmental changes in over- and underattribution. Cognitive Development, 3, 55-70.

Johnston, J. R. (1988). Children's verbal representation of spatial location. In J. Stiles-Davis \& M. Kritchevsky (Eds.), Spatial cognition: Brain bases and development (pp. 195-205). Hillsdale, NJ: Lawrence Erlbaum Associates.

Kay, P., \& Kempton, W. (1984). What is the Sapir-Whorf hypothesis? American Anthropologist, $86,65-79$.

Keil, F. C. (1994). The birth and nurturance of concepts by domains: The origins of concepts of living things. In L. A. Hirschfeld \& S. A. Gelman (Eds.), Mapping the mind (pp. 234-254). New York: Cambridge University Press.

Keil, F. C., \& Batterman, N. (1984). A characteristic-to-defining shift in the development of word meaning. Journal of Verbal Learning and Verbal Behavior, 23, 221-236.

Kolstad, V., \& Baillargeon, R. (1991). Appearance and knowledge-based responses to containers in infants. Unpublished manuscript. 
Kotovsky, L., \& Gentner, D. (1996). Comparison and categorization in the development of relational similarity. Child Development, 67, 2797-2822.

Kuczaj, S. A., Borys, R. H., \& Jones, M. (1989). On the interaction of language and thought: Some thoughts and developmental data. In A. Gellatly, D. Rogers, \& J. Slaboda (Eds.), Cognition and social worlds. Oxford, England: Oxford University Press.

Kurtz, K. J., \& Gentner, D. (1998, November). The mechanisms of mapping: Evidence from on-line judgments of analogy. Poster session presented at the 39th Annual Psychonomic Society, Dallas, TX.

Li, P., \& Gleitman, L. (1999). Turning the tables: Language and spatial reasoning (Tech. Rep.). University of Pennsylvania.

Loewenstein, J., \& Gentner, D. (1998, August). Relational language facilitates analogy in children. Proceedings of the Twentieth Annual Conference of the Cognitive Science Society (pp. 615-620). Mahwah, NJ: Lawrence Erlbaum Associates.

Loewenstein, J., \& Gentner, D. (2001). Spatial mapping in preschoolers: Close comparisons facilitate far mappings. Journal of Cognition and Development, 2(2), 189-219.

Loewenstein, J., Thompson, L., \& Gentner, D. (1999). Analogical encoding facilitates knowledge transfer in negotiation. Psychonomic Bulletin Eo Review, 6(4), 586-597.

Lucy, J. A. (1992). Language diversity and thought: A reformation of the linguistic relativity hypothesis. Cambridge, England: Cambridge University Press.

Lucy, J. A. (1994). Grammatical categories and cognition. Cambridge: Cambridge University Press.

Lucy, J. A. (1996). The scope of linguistic relativity: An analysis and review of empirical research. In J. J. Gumperz \& S. C. Levinson (Eds.), Rethinking linguistic relativity (pp. 37-69). Cambridge, England: Cambridge University Press.

Lucy, J. A., \& Shweder, R. A. (1979). Whorf and his critics: Linguistic and nonlinguistic influences on color memory. American Anthropologist, 81, 581-618.

Mandler, J. M., \& McDonough, L. (1993). Concept formation in infancy. Cognitive Development, 8, 291-318.

Markman, A. B., \& Gentner, D. (1990). Analogical mapping during similarity judgments. Proceedings of the Twelfh Annual Conference of the Cognitive Science Society, 38-44.

Markman, A. B., \& Gentner, D. (1993). Structural alignment during similarity comparisons. Cognitive Psychology, 25, 431-467.

Markman, A. B., \& Gentner, D. (1996). Commonalities and differences in similarity comparisons. Memory and Cognition, 24(2), 235-249.

Markman, E. M. (1989). Categorization and naming in children: Problems of induction. Cambridge, MA: MIT Press.

Markman, E. M., \& Hutchinson, J. E. (1984). Children's sensitivity to constraints on word meaning: Taxonomic versus thematic relations. Cognitive Psychology, 16, 1-27.

Medin, D. L., Goldstone, R. L., \& Gentner, D. (1993). Respects for similarity. Psychological Review, 100(2), 254-278.

Mehler, J., \& Dupoux, E. (1994). What infants know. Malden, MA: Blackwell.

Meltzoff, A. N. (1988). Infant imitation and memory: Nine-month-olds in immediate and deferred tests. Child Development, 59, 217-225.

Namy, L. L., \& Gentner, D. (in press). Making a silk purse out of two sow's ears: Young children's use of comparison in category learning. Journal of Experimental Psychology: General.

Nelson, K. (1996). Language in cognitive development: The emergence of the mediated mind. Cambridge: Cambridge University Press.

Novick, L. R. (1988). Analogical transfer, problem similarity, and expertise. Journal of Experimental Psychology: Learning, Memory, and Cognition, 14, 510-520.

Nunes, T., Schliemann, A. D., \& Carraher, D. W. (1993). Street mathematics and school mathematics. New York: Cambridge University Press.

Piaget, J. (1951). The child's conception of physical causality. London: Routledge \& Kegan Paul. 
Piaget, J. (1952). The origins of intelligence in children. New York: International Universities Press.

Piaget, J. (1954). The construction of reality in the child. New York: Basic Books.

Piaget, J. (1955). The language and thought of the child. New York: World Publishing.

Pinker, S. (1989). Learmability and cognition: The acquisiton of argument structure. Cambridge, MA: MIT Press.

Pinker, S. (1994) The language instinct. New York: Morrow.

Pirolli, P. L., \& Anderson, J. R. (1985). The role of learning from examples in the acquisition of recursive programming skills. Canadian Joumal of Psychology, 39, 240-272.

Rattermann, M. J., \& Gentner, D. (1998). The effect of language on similarity: The use of relational labels improves young children's performance in a mapping task. In K. Holyoak, D. Gentner, \& B. Kokinov (Eds.), Advances in analogy research: Integration of theory $\mathcal{E}^{\circ}$ data from the cognitive, computational, and neural sciences (pp. 274-282). Sofia: New Bulgarian University.

Rattermann, M. J., \& Gentner, D. (submitted). The effect of language on similarity: The use of relational labels improves young children's analogical mapping performance.

Rattermann, M. J., Gentner, D., \& DeLoache, J. (1987, April). Young children's use of relational similarity in a transfer task. Poster session presented at the biennial meeting of the Society for Research in Child Development, Baltimore, MD.

Reeves, L. M., \& Weisberg, R. W. (1994). The role of content and abstract information in analogical transfer. Psychological Bulletin, 115(3), 381-400.

Rips, L. J. (1975). Inductive judgments about natural categories. Journal of Verbal Learning and Verbal Behavior, 14, 665-681.

Rogoff, B. (1990). Apprenticeship in thinking: Cognitive development in social context. New York: Oxford University Press.

Ross, B. H. (1987). This is like that: The use of earlier problems and the separation of similarity effects. Jourmal of Experimental Psychology: Learming, Memory, and Cognition, 13(4), 629-639.

Ross, B. H. (1989). Some psychological results on case-based reasoning. In Proceedings: Casebased reasoning workshop (pp. 144-147). San Mateo, CA: Morgan Kaufmann.

Rovee-Collier, C. K., \& Fagen, J. W. (1981). The retrieval of memory in early infancy. In L. P. Lipsett (Ed.), Advances in infancy research, 1 (pp. 225-254). Norwood, NJ: Ablex.

Rutherford, E. (1906). Radioactive transformations. New York: C. Scribner's Sons.

Sapir, E. (1949/1924). The grammarian and his language. In D. G. Mandelabum (Ed.), The selected writings of Edward Sapir in language, culture, and personality. Berkeley, CA: University of California Press.

Scholnick, E. K., \& Hall, W. S. (1991). The language of thinking: Metacognitive and conditional words. In S. A. Gelman \& J. P. Byrnes (Eds.), Perspectives on language and thought: Interrelations in development (pp. 225-277). London: Cambridge University Press.

Scholnick, E. K., \& Wing, C. S. (1982). The pragmatics of subordinating conjunctions: A second look. Journal of Child Language, 9, 461-479.

Shatz, M. (1991). Using cross-cultural research to inform us about the role of language in development: Comparisons of Japanese, Korean, and English, and of German, American English, and British English. In M. H. Bornstein (Ed.), Cultural approaches to parenting (pp. 139-153). Hillsdale, NJ: Lawrence Erlbaum Associates.

Simon, D. J., \& Keil, K. C. (1995). An abstract to concrete shift in the development of biological thought: The inside story. Cognition, 56, 129-163.

Simon, T. J., \& Klahr, D. (1995). A computational theory of children's learning about number conservation. In T. J. Simon \& G. S. Halford (Eds.), Developing cognitive competence: New approaches to process modeling (pp. 315-354). Hillsdale, NJ: Lawrence Erlbaum Associates. 
Slobin, D. I. (1996). From "thought and language" to "thinking for speaking." In J. J. Gumperz \& S. C. Levinson (Eds.), Rethinking linguistic relativity (pp. 70-96). Cambridge, England: Cambridge University Press.

Smith, L. B. (1989). From global similarities to kinds of similarities: The construction of dimensions in development. In S. Vosniadou \& A. Ortony (Eds.), Similarity and analogical reasoning (pp. 146-178). New York: Cambridge University Press.

Smith, L. B. (1993). The concept of same. In H. W. Reese (Ed.), Advances in child development and behavior (Vol. 24, pp. 215-252). San Diego, CA: Academic Press.

Smith, L. B., \& Sera, M. D. (1992). A developmental analysis of the polar structure of dimensions. Cognitive Psychology, 24(1), 99-142.

Spelke, E. S. (1988). Where perceiving ends and thinking begins: The apprehension of objects in infancy. In A. Yonas (Ed.), Perceptual development in infancy: Minnesota Symposia on Child Psychology, 20 (pp. 197-234). Hillsdale, NJ: Lawrence Erlbaum Associates.

Spelke, E. S. (1990). Principles of object perception. Cognitive Science, 14, 29-56.

Thompson, L., Gentner, D., \& Loewenstein, J. (2000). Avoiding missed opportunities in managerial life: Analogical learning improves case-based transfer. Organization Behavior and Human Decision Processes, 82(1), 60-75.

Tomasello, M. (1995). Pragmatic contexts for early verb learning. In M. Tomasello \& W. E. Merriman (Eds.), Beyond names for things: Young children's acquisition of verbs (pp. 115-146). Hillsdale, NJ: Lawrence Erlbaum Associates.

Tomasello, M. (1999). The cultural origins of human cognition. Cambridge, MA: Harvard University Press.

Uttal, D. H., Schreiber, J. C., \& DeLoache, J. S. (1995). Waiting to use a symbol: The effects of delay on children's use of models. Child Development, 66, 1875-1889.

Vosniadou, S. (1989). Analogical reasoning as a mechanism in knowledge acquisition: A developmental perspective. In S. Vosniadou \& A. Ortony (Eds.), Similarily and analogical reasoning (pp. 413-437). New York: Cambridge University Press.

Vygotsky, L. (1962). Thought and language. Cambridge, MA: MIT Press. (Original work published 1934)

Waxman, S. R. (1990). Linguistic biases and the establishment of conceptual hierarchies: Evidence from preschool children. Cognitive Development, 5, 123-150.

Waxman, S. R., \& Gelman, R. (1986). Preschoolers' use of superordinate relations in classification and language. Cognitive Development, 1, 139-156.

Waxman, S. R., \& Hall, G. (1993). The development of a linkage between count nouns and object categories: Evidence from fifteen- to twenty-month-old infants. Child Development, $64,1224-1241$.

Waxman, S. R., \& Kosowski, T. (1990). Nouns mark category relations: Toddlers' and preschoolers' word-learning biases. Child Development, 61, 1461-1473.

Waxman, S. R., \& Markow, D. B. (1995). Words as invitations to form categories: Evidence from 12- to 13-month-old infants. Cognitive Psychology, 29, 257-302.

Whorf, B. L. (1956). Science and linguistics. In J. B. Carroll (Ed.), Language, thought and reality: Selected uritings of Benjamin Lee Whorf (pp. 207-219). Cambridge, MA: MIT Press.

Wilcox, S., \& Palermo, D. S. (1980). "In," "on," and "under" revisited. Cognition, 3(3), 245-254.

Wolff, P., \& Gentner, D. (2000). Evidence for role-neutral initial processing of metaphors. Journal of Experimental Psychology: Learming, Memory, and Cognition, 26(2), 529-541. 